\title{
Os Guarani na fronteira do Brasil, Paraguay e Argentina: uma viagem de intercâmbio Guarani ${ }^{1}$
}

\author{
Antonio Brand, UCDB/MS/Brasil ${ }^{2}$ \\ Rosa Sebastiana Colman, UCDB/MS/Brasil ${ }^{3}$
}

Resumo: O presente artigo é resultado da participação em viagem de intercâmbio entre os Guarani Mbya, Ñandeva e Kaiowá/Paĩ, do Paraguay, Brasil e Argentina, realizada entre os dias 30 de Março e 06 de Abril de 2009, com a participação de 13 representantes indígenas dos três países. O objetivo desse intercâmbio era, além de conhecer a realidade vivenciada nos três países, fortalecer as articulações entre os Guarani. A iniciativa está inserida num projeto voltado para o "Apoio ao Fortalecimento das Políticas Públicas entre os Índios Guarani na Região Transfronteiriça: Brasil, Paraguai e Argentina", desenvolvido por diversas Universidades do Brasil, Paraguai e Argentina, com apoio do Ministério Público Federal e recursos da agência espanhola de cooperação (AECID). As visitas foram documentadas por escrito e filmadas por representantes guarani. Algumas observações conclusivas podem ser destacadas. A constatação de problemas comuns relacionados à posse dos territórios guarani nos três países, o comprometimento dos recursos naturais em toda a extensão do território e, em especial, a crescente interferência das fronteiras nacionais sobrepondo-se e remodelando as fronteiras indígenas, apesar da persistência da mobilidade transfronteiriça dos Guarani.

Palavras-chave: Os Guarani, Fronteiras Nacionais, Territórios e Recursos Naturais, Mobilidade transfronteiriça

\section{Introdução:}

Os Guarani, seus diversos sub-grupos, quando da chegada dos colonizadores espanhóis, no século XVI, ocupavam uma ampla extensão de terras, que ia desde o litoral de Santa Catarina, ao longo do Rio Paraguai, Paraná, Apa e Miranda, chegando até o Chaco boliviano. A partir de 1750 (Tratado de Madrid), os Guarani confrontam-se de forma cada vez mais direta com as fronteiras dos Estados Nacionais, alterando e desfigurando o território indígena. Como resultado de processos distintos, em 1811, verifica-se a independência do Paraguai e, em 1822, a independência do Brasil. Os Caaguá, ou Caayguá ou, ainda, Cainguá, ou Guarani, certamente, nem tomaram conhecimento desses acontecimentos, embora a sua relação com as frentes de ocupação,

\footnotetext{
${ }^{1}$ Trabalho apresentado na $27^{\mathrm{a}}$. Reunião Brasileira de Antropologia, realizada entre os dias 01 e 04 de agosto de 2010, Belém, Pará, Brasil. Pesquisa que conta com apoio do CNPq.

${ }_{2}$ Doutor em História e Coordenador do Programa Kaiowá/Guarani - NEPPI/UCDB. E-mail: brand@ucdb.br

${ }^{3}$ Mestre em Desenvolvimento Local/UCDB, pesquisadora do Programa Kaiowá Guarani/NEPPI/UCDB. E-mail: rosacolman01@yahoo.com.br
} 
em especial com os crioulos ${ }^{4}$, modifique-se, profundamente.

Os Guarani e populações falantes do idioma guarani, no século XVI, ocupavam um amplo território nas terras baixas da América do Sul, que ia desde o litoral de Santa Catarina, ao longo do Rio Paraguai, Paraná, Apa, Miranda e Pilcomayo, chegando até as franjas da cordilheira dos Andes. A partir de 1775, os Guarani confrontam-se com as fronteiras dos Estados Nacionais, alterando e desfigurando as antigas fronteiras indígenas.

Atualmente, os Guarani seguem presentes em cinco países do MERCOSUL, com uma população estimada em 225 mil pessoas e, apesar das crescentes imposições jurídico-estatais, seguem mantendo suas dinâmicas de definição e redefinição das fronteiras culturais, persistindo as redes sociais, com intensas e variadas trocas entre parentes, que residem nos diversos países. O conhecido mapa etno-histórico de Kurt Nimuendajú (1981) mostra a grande mancha amarela que identifica, graficamente, o território dos Guarani ao sul do paralelo 22, em terras não limitadas pelas atuais fronteiras do Brasil, Paraguai, Bolívia e outros estados.

Contatados desde 1505 (MELIÀ, 2008), os Guarani constituíam, no período colonial, diversos grupos dialetais e culturais, que formavam, contudo, uma grande unidade a ponto de os primeiros conquistadores os denominarem a todos de Guarani (não se trata, portanto de autodenominação).

A assim denominada região do Prata, no período colonial e pós-colonial, sempre foi um espaço de fortes conflitos territoriais, primeiramente, entre as Coroas Portuguesa e Espanhola e, num segundo momento, a partir de 1810, entre os países resultantes dos processos de autonomia e constituição dos Estados Nacionais na América. Um marco político importante na definição das fronteiras regionais é constituído pelo Tratado de Madri, de 1750, orientado, especialmente, pelo critério de “fronteiras naturais", seguindo rios e montanhas (MARTIN, 1992, p. 83), ignorando, portanto, as fronteiras do território tradicional guarani. Firma-se, no século XVIII, o princípio jurídico do "uti possidetis", adquirindo importância cada vez maior a política de "fronteiras vivas".

Os Guarani, desde o período colonial, sempre foram marcados ou

\footnotetext{
${ }^{4}$ Crioulo é termo que designa a nova elite política pós-independência nas Américas. São os descendentes de espanhóis nascidos na América.
} 
demarcados pelo estado. Esta demarcação não ocorreu somente no período republicano. Porém, como uma sociedade sem Estado ou até contra o Estado (ver CLASTRES, 1978, MELIÁ, 2008), os Guarani, assim como o fizeram no período colonial, seguem até o presente resistindo a esses enquadramentos.

Melià, G. Grünberg e F. Grünberg (1976), referindo-se aos Itatin, reconhecem que nos séc. XVI e XVII, estes eram vistos pelos novos chegantes como um povo a ser conquistado ou reduzido, como inimigos temidos ou aliados importantes. Com a criação dos Estados Nacionais, esses Caaguá - povos da mata - pouco a pouco passam a ser considerados como grupos marginais ou periféricos, que interessam às frentes de expansão, inicialmente, como mão-de-obra (na coleta da erva-mate e depois para efetuar as derrubadas das matas). Num segundo momento, passam a ser percebidos mais como um estorvo para a ocupação dos seus espaços por frentes não-indígenas.

Lançando um olhar sobre esse longo processo que se segue à implantação dos Estados Nacionais, percebe-se que os tempos, as formas e os impactos sobre os Guarani da ocupação do território indígena e da exploração de sua mão-de-obra mostram-se crescentemente diferenciadas em cada estado nacional, no decorrer do século $\mathrm{XX}$, adquirindo, porém, características mais próximas e comuns no final desse século e início do século XXI, em decorrência da presença, em ambos ao lados da fronteira do Brasil e do Paraguai, de uma nova frente de ocupação, caracterizada pelo agronegócio, tema não incluído nessa abordagem.

O povo guarani encontra-se, hoje, distribuído pela Bolívia, Paraguai, Uruguai, Brasil e Argentina, sendo que o idioma guarani, em suas diversas variedades dialetais, é o único falado nesses países. Por essa razão, a língua guarani pode ser considerada como a "língua histórica" do MERCOSUL.

No Brasil, a população guarani é de aproximadamente 52 mil índios, subdivididos em três grupos lingüísticos: Nhandeva, Kaiowá e Mbyá ${ }^{5}$. Vivem, hoje, em dezenas de aldeias espalhadas por mais de 100 municípios brasileiros, em dez estados. Na Argentina, em 1998, estimava-se que havia 27.680 Chiriguano, 2.325 Chané guaranizados e 3.500 Mbya. No Uruguay calcula-se uma população Guarani Mbya de 600 indivíduos, enquanto que no Paraguai, no mesmo ano, os Chiriguano foram estimados em 3.000 indivíduos, os Chiripá, em 6.500, os Pai/Kayová, em 11.000 e os

\footnotetext{
${ }^{5}$ Os Ñandeva são os únicos a se auto-identificarem como guarani.
} 
Mbya, em $2.460^{6}$.

\section{Os Guarani e suas fronteiras}

Tradicionalmente os guarani se territorializavam de acordo com vários fatores: a disponibilidade de locais com recursos naturais considerados apropriados, ou seja, locais livres de ameaças sobrenaturais; a proximidade de parentelas aliadas; a habilidade do líder em reunir a parentela e resolver os problemas e a incidência ou não de doenças ou mortes (PEREIRA, 2007).

Os Guarani trabalham com noções e conceitos próprios de fronteira, uma idéia mais sociológica e ideológica, que inclui e exclui, definindo quem pertence e quem não pertence à determinada coletividade, estabelecendo os limites a partir dos quais eles não se sentem “a gosto" (MELIÀ, 2007) ${ }^{7}$. A prática guarani de fronteira tem relação com a ecologia, o parentesco e a economia.

Nesse sentindo, para Brand (et al, 2008, s/p.):

É importante ter presente que a discussão sobre identidade guarani remete, diretamente, para a idéia de pertencimento e para as relações de parentesco - atualizadas por filiação e descendência, memória, comunicação. São Guarani aqueles que se assumem como descendentes e que são reconhecidos como tais, sendo que a idéia de cidadania guarani específica está associada ao conceito de pertencimento. Daí a importância da concepção de território como espaço de comunicação, com as suas marcas referidas e atualizadas pela memória.

Segundo Melià (2007), os territórios indígenas seriam, acima de tudo, “territórios de comunicação", prenhes de memória e de história, que podem ser visualizados por marcas, tais como, caminhos, casas, recursos naturais e acontecimentos específicos. Referindo-se às fronteiras guarani, Melià (2007) entende que são parte da sua identidade, remetendo para o seu modo de ser. O território é o espaço no qual as relações de parentesco, com suas complexas redes de comunicação, se reproduzem. Por isso, sob a ótica indígena, essas fronteiras podiam ser relativizadas em determinados casos, como casamentos ou pelas dinâmicas de alianças. Essas redes seguem, no presente, plenamente em vigor, constituindo e desconstituindo fronteiras, entendidas

\footnotetext{
${ }^{6}$ Fonte: www.campanhaguarani.org.br

${ }^{7}$ Relatório da Reunião sobre o projeto Os Guarani no MERCOSUL, Foz de Iguaçu, Novembro de 2007
} 
como dinâmicas e não fixas.

Não fazem sentido para os Guarani, as fronteiras nacionais, embora, desde o período colonial, sua história venha, fortemente, marcada e demarcada pelas fronteiras do estados nacionais. Porém, é importante destacar que desde o período colonial, os Guarani buscam ignorá-las, resistindo a esse tipo de enquadramento. Durante a presente viagem foi possível constatar, como, para os Guarani, essas fronteiras seguem não fazendo sentido, pois todos os participantes da viagem sentiam-se e reconheciam-se como parentes.

A história de vida de um dos integrantes dessa viagem, Santiago Franco ${ }^{8}$, permite compreender bem essa afirmação. Ele nasceu no Paraguai, morou na Argentina e agora mora em Porto Alegre, no Brasil. Logo no início da viagem já se reencontrou com seu tio, Hilário Acosta, morador da Província de Misiones, AR, outro participante da viagem, que a muito tempo não via. E, assim, em quase todas as aldeias visitadas, os participantes da iniciativa encontravam parentes e ou conhecidos.

Porém, ficou claro, também, que apesar dos esforços dos Guarani em ignorar as fronteiras nacionais, essas interpõem dificuldades crescentes à sua circulação e a seus direitos, como bem expressa o depoimento do mesmo Santiago: "Os governos nos limitando, dividindo-nos deixando sem espaço, negando nossos direitos!”.

Da mesma forma, outro participante, Joaquim Adiala Hara", afirma: "Nós Guarani que somos Mbya, Guarani Ñandéva, Kaiowa, Paĩ Tavyterã, não somos diferentes porque sempre fomos um grande povo, com autonomia e sem fronteira. Somos os verdadeiros donos dessa imensa terra que se chama América". Seu depoimento confirma a percepção guarani sobre as fronteiras nacionais.

A necessidade de, a cada momento, ter que pedir licença nas aduanas/alfândegas e comunicar a saída e entrada nos diversos países gerava uma situação de visível incômodo aos integrantes da viagem. "Por que não se tem liberdade para circular livremente nos três países"?, perguntavam eles, considerando, especialmente, que "guarani é guarani em todos os lugares".

\footnotetext{
${ }^{8}$ Santiago Franco é guarani Mbya e reside no Rio Grande do Sul.

${ }^{9}$ Ava Guarani de Porto Lindo, Japorã/MS.
} 


\section{Intercâmbio Guarani}

Foi realizada, entre os dias 29/03 a 06/04 de 2009, uma viagem de intercâmbio entre os diversos grupos guarani, localizados no Paraguai, Argentina e Brasil. Esta viagem tinha por objetivo "Permitir um intercambio entre os Guarani localizados nas fronteiras dos três países (Brasil, Paraguai e Argentina), tendo em vista ampliar e fortalecer o intercâmbio e a articulação entre eles, tendo em vista, especialmente, a questão das políticas públicas”.

Participaram da viagem os Guarani: Hilário Acosta, Mbya da aldeia Takuapi e Nicanor Benítes, Mbya da aldeia Tekoa Arandu, ambas de Misiones, Argentina; Luiz Arce, Paĩ Tavyterã da aldeia Itaguasu, Rafael Recalde, Mariano Ferreira, Lorença Fernandes, os três são Ava Guarani da aldeia Jukyry, todas localizadas no Paraguay; Nelson Cabreira, Antonia Cabreira, Alicelia Cabreira, os três são Kaiowá da aldeia Karumbe, Lídio Cavanha Ramires, Kaiowá, da aldeia Te’ýi Kue, Plácido Romero, Kaiowá da aldeia Ñanderu Marangatu, Joaquim Adiala, Ava Guarani, da aldeia Porto Lindo e Santiago Franco, Mbya, de Porto Alegre, aldeias localizadas no Brasil, além de dois não indígenas que acompanharam a viagem: Egon Heck (Conselho Indigenista Missionário - CIMI) e Rosa Sebastiana Colman (Universidade Católica Dom Bosco UCDB), de Campo Grande/MS, representante da equipe de coordenação do Projeto Apoio ao Fortalecimento das Políticas das Políticas Públicas entre os Guarani na Região Transfronteiriças. ${ }^{10}$

No dia 30 de março, todos os integrantes da viagem encontraram-se em Ponta Porã/MS/BR. Nesse mesmo dia foi realizada visita à aldeia Itaguasu, dos Paĩ tavyterã, no Paraguai. À tarde, à aldeia Kaiowá Ñanderu Marangatu, no Município de Antônio João/MS/BR. No dia seguinte, dia 31/03, pela manhã, foi visitado o acampamento Kurusu Amba, localizado em Coronel Sapucaia, de indígenas da etnia Kaiowa, que reivindicam sua terra, e, em seguida, a Aldeia Porto Lindo e Yvy Katu, no

\footnotetext{
${ }^{10}$ A viagem seguiu um roteiro, construído de forma coletiva, ouvindo, previamente, sugestões de órgãos parceiros no Paraguay, Argentina e Brasil. Um dos participantes, Lídio Cavanha, Kaiowá de Caarapó, Mato Grosso do Sul, foi responsável pelas filmagens durante a viagem. Vários outros participantes da viagem, também, fizeram amplo registro fotográfico. E, ao final da viagem, os integrantes da comissão apresentaram a proposta de uma edição das imagens feitas durante o percurso. Escolheram três representantes, um de cada país, para fazerem essa edição, tendo em vista, inclusive, aprender como se edita um vídeo. Esta atividade contou com o apoio da UNFPA - Fundo de População das Nações Unidas ONU-Brasil.
} 
município de Japorã/MS/BR.

Nos dias 01 e 02/04 foram visitadas as aldeias Ava Guarani: Jukyry, Ko’ẽju e Arroyo Guasu, no Departamento Alto Paraná, no Paraguay. No dia 03/04, a aldeia Mbya Guavirami, no Departamento de Itapúa, no Paraguay e nos dias 04 e 05/04, já na região de Misiones, na Argentina, foram visitadas as aldeias Mbya, de Ka'akupe, Kapi'i Poty, Alecrin e Tekoa Arandu. No dia 06/04, a aldeia Okoy, próximo à Foz do Iguaçu, Brasil. Entre os dias 06, 07 e 08 toda a comissão participou do Seminário de Planejamento das atividades do Projeto dos Guarani Transfronteiriços, em Foz do Iguaçu/PR/BR.

Considerando o relato dos participantes, a questão da terra foi, certamente, o aspecto mais destacado, tendo em vista a situação vivida nos três países. Para Santiago Franco "A primeira questão é a terra 'Yvy Rupa', nossa terra. Estão nos negando. Causando muito sofrimento!" $\mathrm{Na}$ mesma linha segue o depoimento de Nicanor Benítes ${ }^{11}$ : "Que reconheçam nossas terras. Vamos seguir lutando por isso". Mais forte é a denúncia de Plácido Romero: "Estão fazendo com nós como animal. Não querem reconhecer nosso espaço, nossa terra”. Hilário Acosta ${ }^{12}$ conclui que: “En los tres países tenemos los mismos problemas en cuanto a los territorios".

É fácil entender a importância dos territórios para os diversos grupos guarani. Segundo Melià, G. Grünberg e F. Grünberg (1976, p. 190):

La conceptualización ñane retã es por tanto el de una territorialidad política. En este caso es también el lugar que Ñande Ru extendió y amojonó para que los Paĩ usen esta tierra que les fue designada; esta patria recibe nombres sagrados. Nane retã y su particularización, ñande rekoha, es el lugar, como lo indica la misma composición de la palabra, donde se sitúa y donde es posible ñande reko. Por esta razón por la que el asunto tierra es de primordial importancia.

A importância da terra para os guarani, também, foi anotado por Egon Heck, um dos participantes da viagem: "[...] ficou claro que existem leis que garantem os direitos indígenas. Porém, na prática, essas leis, incluindo as leis internacionais, são desrespeitadas. Especialmente a garantia dos territórios Guarani” (HECK, 2009, p. 7).

Outro aspecto que está diretamente relacionado à problemática das terras e foi bastante destacado pelos participantes da viagem diz respeito à situação de violência sofrida, principalmente, pelas lideranças, que são assassinadas e os responsáveis não

${ }^{11}$ Guarani Mbya de Tekoa Arandu/Missiones/AR.

${ }^{12}$ Guarani Mbya de Takuapi/Missiones/AR. 
punidos. É o que ressalta de alguns depoimentos: “Os fazendeiros matam nossos líderes. A justiça não acontece [...]. Põem pistoleiros, prensam a gente num chiqueirinho... Nós, também, queremos viver" (Plácido Romero). E Joaquim Adiala Hara segue na mesma linha: "As lideranças são assassinadas e os assassinos estão sem punição".

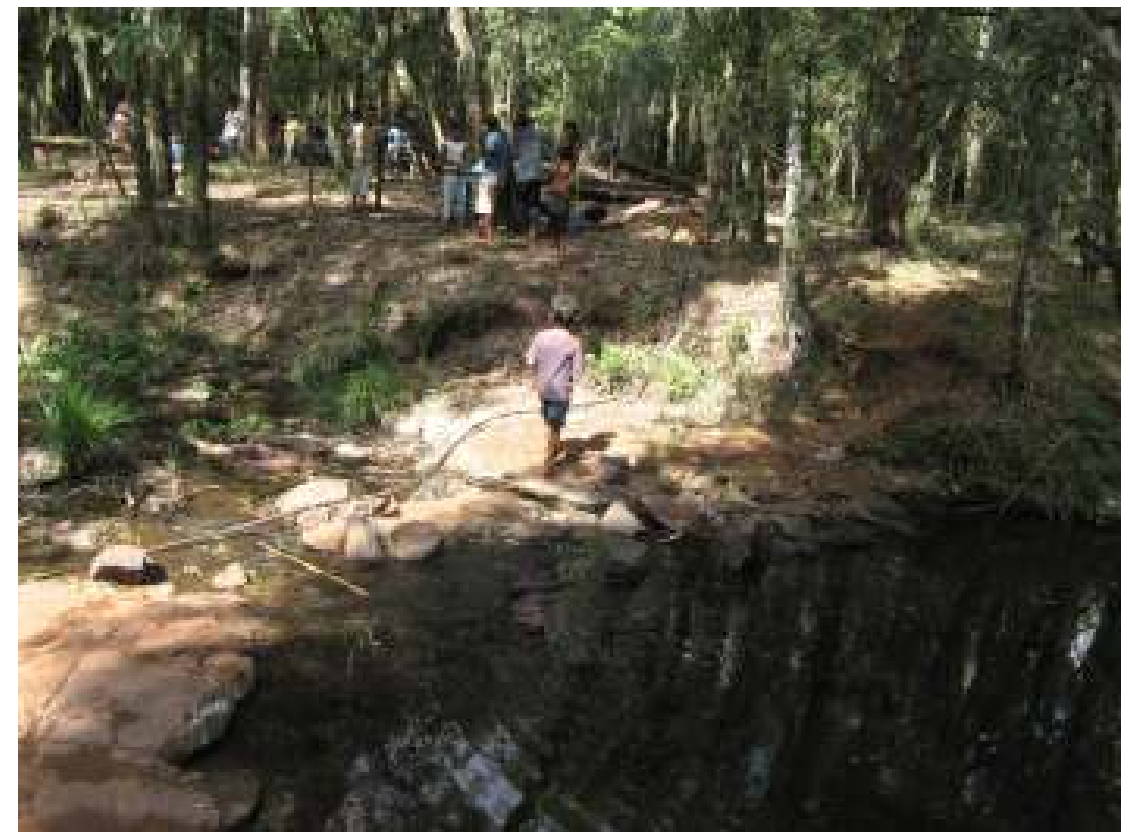

Tekoa Mbya Ka'akupe Misiones/AR (foto Egon Heck)

Os Guarani são conhecidos como povo da mata. Por isso, durante a viagem de intercâmbio, em alguns lugares, como em Ita Guasu, no departamento de Amambay, no Paraguay, aldeia que mantém uma vegetação significativa, estes aspectos ambientais foram experimentados com saudades por quem, atualmente, vive em áreas degradadas. Observou-se a alegria dos participantes ao caminhar pela mata. S. Nelson Cabreira imitava ruídos de pássaros e outros animais. Em algumas aldeias, como de Ko’ẽju, recolheram variedades de sementes e mudas. Da mesma forma o banho no pequeno córrego de Arroyo Guasu se transformou em festa, indicando a relevância dos lugares onde ainda era possível encontrar esses recursos naturais importantes.

Da mesma forma observa Egon Heck:

Era uma alegria para os treze participantes Guarani, quando entrávamos nos caminhos de mata, ou onde ainda existia caça, peixe. Logo iam reconhecendo grande quantidade de plantas medicinais. Iam recolhendo cascas e sementes. Era como um reencontro com o passado. A alegria saltava aos olhos. A caminhada se transformada em leve andar nas sendas de vida, da terra sem males. Era revisitar espaços de sobrevivência. Era flutuar no sonho do futuro (HECK, 
2009, p 6).

Esta imagem pode ser observada na foto a seguir:

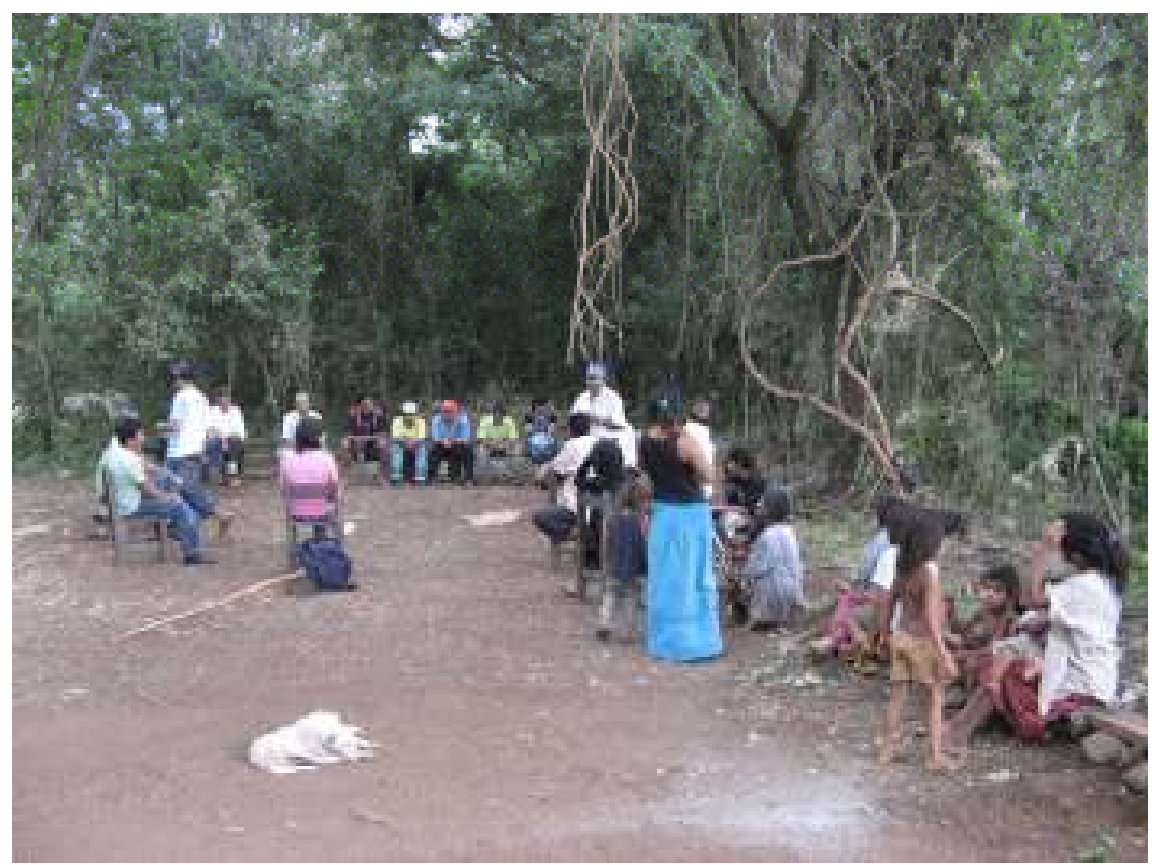

Tekoa mbya Kapi’i Poty Missiones/AR (Foto Egon Heck)

Por outro lado, a destruição dos recursos naturais no território indígena foi denunciada pelos participantes. Plácido Romero afirmou que "acabaram nossa mata". E para Joaquim Adiala Hara: “Os grandes latifundiários estão cada vez mais destruindo matas, solo, poluindo rios e cada vez mais avançando em busca do tal "progresso"". Hilário Acosta relata a importância dos recursos naturais e como a cosmologia, o modo de ser guarani, se relaciona diretamente com os recursos naturais:

Por eso no queremos que tumben el monte que tenemos porque nos da muchas cosas, nos protege del viento y las tormentas; de ahí sacamos muchos remedios y frutas. Cuando llega el momento de poner nombres a los chicos le pido a los colonos que den permiso para sacar, como no es madera linda me dejan. Pero esto también se va terminando, ahora conseguimos poquito. A los más ancianos les duele porque cada vez menos se hacen estas cosas, cuando la gente se enferma tenemos que usar güembé y cada día se consigue menos. Cuando un chico tiene problemas del alma solamente se salva con el güembé. Se hace un ñemogarai para saber por qué está así, por qué no quiere crecer? El Opygua con eso sabe. Es grave no poder dar nombre a los chicos, cuando no tienen nombre no se hallan. Tienen que tener nombre sino su alma no se halla.

A cosmologia guarani, que não dissocia o mundo da natureza e o mundo 
sobrenatural, ficou evidente nessa experiência de intercâmbio. A religiosidade guarani foi um elemento muito significativo na viagem. Participou da iniciativa uma família de xamãs que fizeram a diferença em todo o percurso, tanto com os rituais como, também, pela sabedoria própria dos mais velhos. Os rituais foram significativos nas aldeias visitadas. Em cada local visitado acontecia uma recepção com rezas e rituais. Da mesma forma, as despedidas eram acompanhadas por muitos rituais.

Assim como na cosmologia guarani, o xamã é o responsável pelo equilíbrio na relação das pessoas com o sobrenatural, tão importante para a manutenção da vida na terra, durante a viagem não foi diferente. Se a viagem foi tranqüila e sem problemas, isso foi atribuído à constante intervenção protetora dos xamãs. Tradicionalmente, o xamã tinha a função de cuidar das festas, dos rituais, do batismo de crianças e sementes, do repasse dos mitos e aconselhamentos. Além disto, alguns eram, também, curandeiros. O xamã é chamado de Ñanderu (nosso pai) pelos Kaiowá e Guarani e karai pelos mbya.

Pereira (1999, p.189) avalia que "a existência do tekoha depende diretamente da presença dos líderes religiosos e políticos com reconhecida habilidade para reunir pessoas". Tradicionalmente, os caciques (tekoharuvicha) exerciam uma liderança política e religiosa, simultaneamente. Os constantes rituais em todos os locais por onde passavam parecia amenizar o sofrimento.

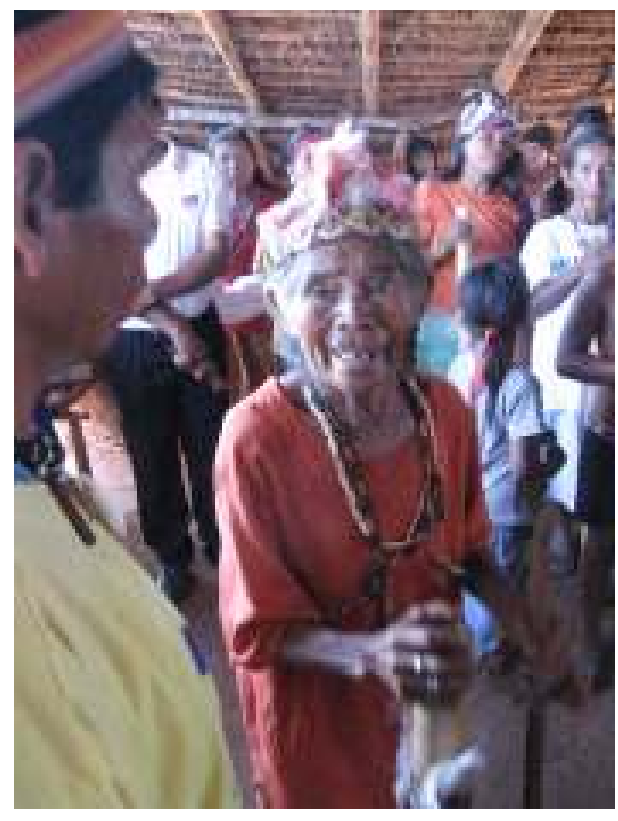

Tekoha Yvy katu, xamã Dominga, Japorã/MS/BR (foto Egon Heck)

Um outro aspecto importante vivenciado durante essa viagem e destacado 
pelos Guarani remete para a importância do caminhar - oguata, muito bem expresso por Santiago: "A caminhada é sagrada. Nosso Deus deixou assim! Ir e vir é pra nós saúde, visitar parente é mais saúde! Uma vitória para nós. O próprio Guarani falando um para o outro!" Santiago Franco). Egon Heck, de forma poética, destaca a mesma idéia:

Povo caminhante. A estratégia do caminho é fazê-lo e dele extrair saúde, energia, vida. Os Guarani são exímios caminhantes. Fazem do caminhar uma luta, a construção de sua territorialidade, a terapia social, a consolidação de alianças. A busca da terra sem males é a bússola (2009, p.7).

O sentido destacado pelos participantes da viagem de intercâmbio pode ser traduzido como visita (jajopou) aos parentes. Os participantes lembravam das visitas aos parentes como um costume dos guarani, realizado tradicionalmente.

Com relação às impressões sobre a viagem manifestadas pelos Guarani, destaca-se a relevância da solidariedade entre as diversos grupos e aldeias, como bem relata Santiago Franco "Quando vi tanto sofrimento, meu coração caiu ao chão! Vi com meus próprios olhos. A realidade e tristeza, gente passando fome". Da mesma forma segue outro relato: "Olhando e ouvindo a gente sente na alma o que o parente está passando. Devemos continuar andando para alimentar a luta, reconquistar nossa liberdade, superar tanto sofrimento e reconstruir nossas terras" (Lídio Cavanha Ramires $)^{13}$. E “sofri com os parentes, mas, também, passamos com eles um pouco de alegria. A floresta é nossa vida (Nicanor Benítes).

Neste sentindo, para Joaquim Adiala: "Os três países dividiram o povo guarani através da fronteira, mas a compaixão, o amor, o afeto, a prosperidade entre o Guarani permanece, ainda".

Diante das dificuldades, os relatos dos participantes apontam, também, para alternativas de solução dos problemas. E aí o fortalecimento da articulação entre os Guarani aparece com destaque: “O contato vai nos fortalecer, politicamente. Quanto mais fui conversando, mais forte e animado fui ficando, para lutar pelos nossos direitos. Fazer o intercâmbio e se articular é um jeito de continuar lutando. Só assim conseguiremos reverter essa situação" (Joaquim Adiala Hara, Guaraniete Mirĩ). Da mesma forma, Santiago Franco, afirmou: "Queremos garantir a cultura rica e viva que temos. Precisamos continuar nossas caminhadas e lutas".

\footnotetext{
${ }^{13}$ Kaiowá da aldeia de Te’ýikue, Caarapó/MS.
} 
Em outro momento, novamente, Joaquim reforça a importância do Guarani acreditar no próprio Guarani: "Não acreditamos muito na justiça do poder político. Acreditamos em nós mesmos, em nossas lutas, em nossos líderes que estão longe e nos que morreram” e, ao mesmo tempo, dá pistas aos governantes de que forma devem agir, sem assistencialismos, como nas palavras de Joaquim: "Não queremos assistencialismo dos políticos nos amarrando nesses conceitos. Queremos que eles sejam nossos parceiros para que nós possamos nos fortalecer na nossa forma de ser e de viver" (Joaquim Adiala).

Avaliando a viagem assim relatou Hilário Acosta:

Es bueno hacer intercambios, no una sola vez. Pienso en los jóvenes, nos tienen que reemplazar y deben ir aprendiendo estas cosas, esto es también capacitación, asi fue para mi. Al volver pude contar todo a mi Comunidad. Ellos mostraron mucho interés, quieren saber como es por allá, como esta la gente, porque si son indígenas son nuestros parientes.

\section{Considerações finais}

É relevante destacar que estamos dialogando com povos indígenas, autóctones, ou aborígenes, povos com direitos inerentes a sua condição de povos précolombianos, que não demandam por políticas assistenciais, mas pelo cumprimento de direitos, inclusive já amplamente garantidos nas legislações de cada país e por diversos dispositivos legais internacionais ${ }^{14}$.

Tem-se, portanto, base legal para iniciar entendimentos no sentido de buscar políticas comuns que não só possam por um fim às práticas que dividem e dificultam as múltiplas relações construídas pelos Guarani, mas viabilizar programas comuns no campo da educação, de formação de professores, políticas lingüísticas, de saúde e de sustentabilidade e, acima de tudo, avançar no processo de defesa das terras indígenas, a partir da compreensão indígena de território. Mas, conforme constata o Relatório da

\footnotetext{
${ }^{14}$ A Convenção 169, da OIT, assinada por todos os países integrantes do Mercosul, em seu Art. 36, afirma que: "Os povos indígenas, em especial os que estão divididos por fronteiras internacionais, têm direito a manter e desenvolver os contatos, as relações e a cooperação, incluídas as atividades de caráter espiritual, cultural, política, econômica e social, com seus próprios membros, assim como com outros povos através das fronteiras. Os Estados, em consulta e cooperação com os povos indígenas, adotarão medidas eficazes, para facilitar o exercício e garantia deste direito".
} 
CEPAL (2007, p. 153) ${ }^{15}$, "el balance de la efectividad de la legislación relativa a los indígenas es crítico", persistindo a violação dos direitos indígenas.

A experiência realizada permitiu a emergência de diversos aspectos importantes do modo de ser dos Guarani, Kaiowá e Mbya, inclusive, aspectos comuns, como a relevância do oguata, dos rituais e da solidariedade. Mostrou, ainda, como, crescentemente, os problemas vivenciados pelos diversos grupos guarani em cada país são cada vez mais próximos ou iguais, em decorrência da pressão do entorno regional sobre os territórios e seus recursos naturais. Finalmente, a experiência desse intercâmbio aponta para a importância dessas visitas e da superação das fronteiras nacionais, como limites a esse intercâmbio, pois não fazem sentido para os Guarani. Inclusive, porque estas já foram há muito tempo relativizadas pelos que ocupam os territórios indígenas ao longo das fronteiras, os grandes proprietários de terra.

\section{Referências}

BRAND, A. J. ; ALMEIDA, Fernando Augusto Azambuja de; FERREIRA, Eva Maria L; COLMAN, Rosa Sebastiana; SOUSA, N. M. de. As Fronteiras Guarani na Província do MT (1749-1910). In: II Seminário Internacional América Platina, 2008, Campo Grande. II Seminário Internacional América Platina. Diálogo Regional e Dilemas Contemporâneos. Campo Grande: fundação Universidade Federal de Mato Grosso do Sul, 2008. v. 1.

BESSA FREIRE, J. R. Observatório Guarani, 2006, mímeo.

CLASTRES, Pierre. A sociedade contra o estado: pesquisa de antropologia política, trad. Théo Santiago, Rio de Janeiro, Francisco Alves, 1978.

HECK, Egon. Os Guarani realizam intercâmbio cultural, p.6 e 7, Porantim, ano XXXI, n. 315, Brasília/DF, maio de 2009.

OIT. CONVENÇÃO 169. Disponível em www.oit.org

MARTIN, André Roberto. Fronteiras e Nações. São Paulo: Contexto, 1992.

MELIÀ, Bartomeu, GRÜNBERG, Georg, GRÜNBERG, Friedl. Los Paĩ-TavyterãEtnografia Guarani del Paraguay contemporáneo. Asunción: Centro de Estudios Antropologicos. Universidad Católica "N.S. de la Asunción”, 1976.

MELIÀ, Bartomeu. El pueblo guaraní: unidad y fragmentos, Mímeo, Assunción, 2008. $12 \mathrm{p}$.

NIMUENDAJÚ, Kurt Unkel. Mapa Etno-Histórico. Brasília: IBGE, 1981.

PEREIRA, Levi Marques. Mobilidade e processos de territorialização entre os kaiowá

${ }^{15}$ CEPAL. Panorama Social de América Latina 2007 (Síntese e Capítulos I a V). Disponível em: $<$ http://www.eclac.org/cgi 
atuais. In História em Reflexão: vol. 1 n. 1 - UFGD - Dourados jan/jun 2007. 33 p. Parentesco e organização social Kaiowá. Dissertação de Mestrado, Universidade estadual de Campinas, Campinas, SP, 1999. 